\title{
The importance of training as a factor in increasing the efficiency and productivity of private sector employees in the UAE
}

\author{
Majid Ahmed Al Qasimi \\ Master of Business Administration, College of Business and Economics, UAE University, \\ United Arab Emirates
}

Email: $\underline{\text { maq1986@outlook.com }}$

\begin{abstract}
:
The research deals with the topic of training and its importance in the development of human resources, which is mainly responsible for increasing the efficiency and productivity of institutions for private-sector employees in the UAE. As both the training of the human factor and the productivity of institutions are the most prominent factors in the stability, continuity, and survival of the institution and its success. The research concluded to clarify the extent of the necessity represented by the training process, as the importance of training lies in giving the new employee the necessary skills to serve his intended duties satisfactorily and accurately. It also encourages and facilitates the capacity of new workers in a way that is in line with the needs of the work and thus performs the work well and thus increases the productivity of the enterprise.
\end{abstract}

Keywords: Training, the efficiency, Productivity, Private Sector, Employees, UAE 


\section{Introduction}

The human element is the basic element in the development of organizations, as the development of human resources is one of the basic tasks that an organization or contemporary society cannot achieve the goal of development without. Where the advanced institutions meet to spend huge sums on training work and on the skills of workers to improve their skills and the efficiency of their products because they are fully aware that the productivity and skills of workers are the paces that they must maintain in addition to the recent developments necessary for them to succeed in achieving their goals efficiently and effectively. In the areas of human resource development, the absorption of new technology.

Where training plays a role in supporting understanding, enhancing skills, developing behavior, and crystallizing trends positively and constructively. As for productivity, it is the relationship between the outputs of various products and services and the inputs from the elements of manufacturing necessary to produce those goods and services. Productivity means that the economic principle permits the use of all or more elements of production so that the optimum production is manufactured at the lowest cost with experience in organization and management. Consequently, the concept of productive efficiency is crystallized by using the specified quantities of those components or making their outputs within their maximum limits and their inputs within their minimum limits, to achieve the maximum possible production.

\section{Research Questions}

The research revolves around the following main question, "What is the importance of training in increasing productivity in the private sector in the UAE?"

Several sub-questions emerge from this main question, as follows:

- What is the concept of training and what are its motives?

- What is productivity and what is its importance?

\section{Research aims}

- Knowing what training is and its motivations for human factors

- Knowing the concept of productivity and explaining its importance to the organization 
- Knowing the importance of training in relation to increasing productivity

\section{Research importance}

Training is very important for developing information, improving their skills, developing their skills, correcting their behavior, and changing their attitudes; Thus achieving full development in the long term. The importance of this study is shown by the fact that people who have true principles and strong behavior if the organization was not working to improve and deepen these valid values, would not continue on the same level.

\section{Search terms}

\section{Training}

The experiences, skills, and attitudes adopted by the employees involved in the project can be shaped or changed through formal practice (Al-Selmi, 1970, 261)

Training is an administrative or institutional attempt to enhance someone's ability to do a certain job or obtain a junior position in the organization for which they work (Shawish, 2000, p.83)

\section{Efficiency}

This definition applies to the company's desire to achieve goals at the lowest cost and harm the employee's job with lower costs (Attia, 2012, p. 45)

\section{Productivity}

Efficient use or substitution of services used by others (other machines or more qualified jobs to improve productivity)

Fayez Al-Zoubi describes productivity as the number of outputs for each variable in a given unit of time, and this means the arithmetic ratio between manufacturing outputs and its inputs from prepared sources.

\section{Previous studies}

The Role of Training in Raising the Productive Efficiency of Banking Workers: Study of Researcher Emad Al-Dhiken Ahmed Al-Sindi Ahmed, Higher Institute for Banking and Financial Studies, 2004 
The study aims to understand the reason for achieving effective production in Sudanese banks by considering the role of training as an important effect in reducing the productivity of Sudanese banks as a traditional way of thinking.

- The case study method is based on the descriptive and experimental approach, whereby the Bank of Sudan was adopted as a representation of the Sudanese banks. The social survey process, which developed the questionnaire and distributed it to a sample of employees of the Bank of Sudan, represents 12 percent of the total number of employees in the 103 questionnaires. A link between training and productivity in production.

-Evaluating the effectiveness of training in raising the efficiency of working women: a study prepared by the researcher Rashid Al-Rashidi, Institute of Public Administration Applied to the Women's Branch, 1996

The research analyzed the most relevant approaches and criteria used to evaluate the effectiveness and impacts of training programs. In contrast, the researcher adopted the descriptive approach to review. One of the researcher's most important recommendations is to ensure that the criteria for preparing government workers are defined. And disseminating information between government agencies and women's organizations.

The Impact of Training on Productive Efficiency: The Study of Dr. Glas et al., An-Najah National University, 2010.

This explanatory research aims to determine the effect of training in the vegetable oil laboratory in Nablus on productivity efficiency among employees and also to determine the role of study variables (employment, university qualifications, number of courses) in the subject of study.

And based on the results of the statistical study, the most important results were the following:

- Training includes technological and cognitive aspects so that the teacher can learn some (technical and cognitive aspects required for work

- Work exercises and skills linked together: improve skills at work with training.

Training increases product quality by enhancing workers' skills and improving manufacturing performance. This training helps increase product quality.

The researchers made the following recommendations: 
- The necessity of consulting employees with the educational programs provided to them by the Department of Human Resources.

- The need to focus on projects that contribute to the quality of production in the facility. Product consistency adds to the experience of the workers and thus increases their production efficiency.

\section{Literature review}

\section{First: What is training?}

The training aims to provide the worker with know-how and knowledge that can improve his experience in doing his work or developing his talents, knowledge, and experiences in a way that enhances his productivity in the success of his current job or training him for more work.

The training has also been described as a positive process of improvement with special directions to deal with a person's actions technically or practically.

To obtain the skills, experiences, and information that an individual must collect, orders, management, and behavioral directions necessary for action; The skills and practices necessary to raise his level of expertise in the conditions necessary for mastery and productivity in speed and cost-saving, as well as the sacrifices made and the hours spent. (The Master, 2001)

\section{Second: Motives for training}

We will find that the educational motives are based on the idea of training and its importance, which we explain as follows: (Bouariba Al Rabeeh, 2007)

1- Improving efficiency: by improving the quantity and quality, preparing workers to carry out their activities with a high degree of perfection, and then increasing their productive capacities.

2. Cost saving: By increasing employee productivity and efficiency, and saving time through understanding work style and performance process, training systems produce more gains than expenses.

3- Raising the morale of employees: through teaching, the employees feel the company's seriousness in providing assistance and their desire, which contributes to enhancing integrity and commitment to the success of their work, and improving their attachment to and strengthening their job. 
4. Provide backup energy: This is necessary to meet the immediate requirements of the manpower, through which the required manpower is planned and trained.

5- Reducing wastefulness: Since employee education includes integrating themselves into their roles and performance processes, building understanding, sensitivity, and a willingness to criticize themselves in a way that does not require more oversight and regulation in their work.

6. Failure to work: Preparation ensures that employees are aware of the best methods of operating the machine, the movement and handling of goods and other materials that lead to industrial accidents, and training to prevent or reduce injuries associated with those activities.

\section{Third: productivity and its importance}

Productivity, in addition to being an essential entry point in overcoming issues of success, individuality, collective production, and in society as a whole, is one of the most important questions that affect economic growth rates in any society and is based on the principles of productivity. Multiply, varies depending on varying expectations.

Productivity in its simple sense is the measure used to determine whether it is goods or service items, and the degree to which the output produced with the resources (inputs) is achieved. (Howayda Al-Awad, 2006)

\section{Important productivity concepts:}

Productivity not only reflects the effectiveness of the job function but also the result of the effectiveness of the output elements the evaluation of the facility's performance and the efficiency of its management is not only done by determining the production, but also by determining the services used for the production.

Just making a profit in an organization or initiative does not inherently imply high productivity.

We need to work with ambiguity carefully (keeping costs down helps raise productivity). As lower costs can lead to a greater decrease in production, thus lowering efficiency. (Bouariba Rabi', 2007) 


\section{The importance of productivity:}

Productivity is critical to help grow the company's internal economy, using the same productive elements without overloading. National efficiency also tends to boost overall production through good use of energy and thus higher living conditions. (Bogloof Wafa, 2017)

\section{Fourth: The importance of training in increasing the productivity of private sector enterprises in the UAE}

The preparation value for the young employee and the elderly worker is based on these basic principles of teaching. The new employee who has just joined the company will not be able to carry out the activities with the necessary expertise and experience.

Therefore the importance of training lies in giving the new employee the skills needed to serve his intended duties satisfactorily and accurately; Also, a person who has previous experience, who recently entered the company, may not have all the potential to work well and in this case, also training is beneficial to perform the required skills. To adapt them to current conditions and situations

Therefore, training in the company encourages and facilitates the ability of new workers in a way that is in line with the needs of the work and thus performs the work well. Moreover, the value and benefits of education are not limited to new workers.

However, its value and benefits often include older workers, so that information can be created and their ability to work improved because research and knowledge are constantly changing.

This includes armed personnel to learn, equip them with new skills and experiences, and support to carry out work successfully and safely through preparation. Business requires continuous improvement of business processes and methods.

On the other hand, preparation is required to prepare employees to take on such higher positions that require higher levels of experience and ability through a technical career or a professional journey, from which the value of training is shown to the ability of workers to take on it. Toplevel jobs and professions. 
Training does not limit its value to employee capacity growth only through knowledge, arts, and skills related to work efficiency, but it extends this important to include the promotion and growth of employees' work behavior and their relationships with the organization and with superiors, supervisors, subordinates and the general organization, meaning that preparation is useful in simplifying procedures and creating valuable beliefs and behaviors. For employees, which ensures that psychological balance is maintained. We also remember that the benefits and value of training include the organization, qualified employees or workers, and the work community.

Training is provided to the company to enhance and develop the capabilities of the employees and thus increase the functional efficiency of the employees and learn new skills that enhance their ability to carry out and develop their current work and enhance the competitiveness of the company.

The trained employee or worker benefits from the training. This gives him a material, moral, and enhanced ability to work for the future and provides him with opportunities to advance to high positions in his future career.

Educated people also actively contribute to the growth of personal relationships within the workplace, which are improved and made more efficient because company members have the experience and capabilities required to do the work; As training is of the utmost importance to improve the experience and awareness of employees at the executive and supervisory levels, as well as where they act within the framework of successful behavioral relationships between them; In addition to training potential managers and equipping them with managerial skills that enable them to take on leadership roles in the future, it is important to improve the capacity of current managers and heads at the various management levels of the company.

The administrative preparation is considered important to deepen and improve managers' ability to manage and effectively define priorities, formulate policies and plans at their various administrative and administrative levels, and evaluate problems. They also adopt scientific decision-making techniques as well as building their capabilities for a comprehensive understanding of their institutions, national, cultural, and economic institutions, departments, traditions, etc. Developing the behavior and thinking of administrators and subordinates and teaching them the behavioral skills to deal effectively. In addition, teaching contributes to 
matching management training with the level of management's ambitions, which are requirements of a psychological nature, and this has been demonstrated in the progress and growth of the institution's competitiveness. Education is an ongoing process that affects all workers and all their jobs.

\section{Conclusion}

The basic principle behind calculating production efficiency is to evaluate the degree of success of the project in the use of effective usable capital, provided that the main function of any project is to achieve its objectives as efficiently as possible. And operating and financial capital, which includes the proper use of all resources and efforts to control their returns. Productivity growth contributes to an increase in national wages, an increase in income, and thus per capita income.

\section{The Results}

Training is a managerial, technological, realistic, and scientific approach that maximizes work efficiency, in ways that improve the use of available human capital at the group or company level.

The training programs offered are helpful and serve their design goals, thus contributing to humble commitment and time optimization in worker productivity.

- In line with the vision of Sheikh Mohammed bin Rashid Al Maktoum, Vice President and Prime Minister and Ruler of Dubai, governmental and private bodies and institutions allocate part of their material capital for training and experience for workers.

\section{Recommendations}

- Analyzing and explaining different jobs, identifying skills, educational programs, and planning.

The role of the direct supervisors of the trainees in establishing and preferring the appropriate preparation and system for their subordinates.

Training supervisors must collaborate to advance the training process

Establishing an effective census plan, which will enable the teacher to benefit from training and a successful outcome reward system that will push the worker to develop his abilities and skills in the workplace. 
Preparing and creating a training schedule to evaluate the objectives of the training programs correctly and simply to meet the actual training needs of the employees, and to choose the appropriate form of preparation.

\section{References}

- Howayda Al-Awad, The Impact of Training on Productive Efficiency, Case Study of Kinana Sugar Company for Employees, Supplementary Research for a Master's Degree in Development Planning, University of Khartoum, 2006

- Bouarioua El Rabie ', The Impact of Training on Enterprise Productivity - Case Study of the Sonelgaz Foundation, Master Study, University of Mohamed Bougara Boumerdache, Algeria, 2007

Boukloof Wafaa, The Role of Training in Raising the Productive Efficiency of the Institution, Master's Study, College of Social Sciences, Al-Arabi Ben Mhidi University - Oum El Bouaghi, Algeria, 2017

- Ali Al-Salami, People Management and Productive Efficiency, Cairo, Gharib Library, Third Edition, 1985 AD.

- Nader Ahmad Abu Sheikha, Productive Efficiency and Means to Improve It, Amman, Jordan, Arab Organization for Administrative Sciences, Al-Dustour Commercial Press, 1982.

- Shawish, Mustafa Naguib (1996) Human Resources Management, People Management. Amman: Sunrise House for Publishing and Distribution.

- Al-Arabi, Attia (2012) The Impact of Using Information Technology on the Job Performance of Workers in Higher Governmental Agencies. Researcher Journal. University of Qasidi Merbah and Ouargla - Algeria -. The tenth issue.

Copyright (C) 2021 Majid Ahmed Al Qasimi, AJRSP. This is an open-access article distributed under the terms of the Creative Commons Attribution License (CC BY NC).

DOI: $\underline{\text { doi.org/10.52132/Ajrsp.e.2021.254 }}$ 